\title{
Direction of Flow of Suspended Particulate Matter in Kwa Ibo River and Boreholes Located Within the Premises of Micheal Okpara University of Agriculture-Umudike
}

\author{
Udoinyang Ifiok Efiong ${ }^{1} \&$ M. U. Igboekwe ${ }^{1}$ \\ ${ }^{1}$ Department of Physics, Micheal Okpara University of Agriculture, Umudike Abia State, Nigeria \\ Correspondence: Udoinyang Ifiok Efiong, Department of Physics, Micheal Okpara University of Agriculture, \\ Umudike Abia State, Nigeria. E-mail: Ifomag@yahoo.com
}

Received: June 21, 2012 Accepted: July 16, 2012 Online Published: August 23, 2012

doi:10.5539/eer.v2n2p92 URL: http://dx.doi.org/10.5539/eer.v2n2p92

\begin{abstract}
This study was carried out to assess the direction of flow of suspended particulate matter in boreholes located within the premises of Micheal Okpara University of Agriculture Umudike (MOUAU) Abia State, Nigeria. Fourteen (14) Vertical Electrical Sounding (VES) were taken in four traverses within the premises and immediate environment of MOUAU. The pattern of groundwater flow within the study locations was deciphered through the use of elevation or hydraulic heads which were determined using Global Positioning System GPS. Water samples were taken from boreholes within the premises of MOUAU and along the banks of Kwa Ibo River bordering the University. The water samples were analysed for physical and chemical properties. Suspended particulate matter and the turbidity were identified and compared to WHO standard. In most well locations, the suspended particulate matters were not sufficient enough to contaminate the ground water except at the CNAS and Zennith bank locations, which have suspended particulate load of $1200 \mathrm{~g} / \mathrm{L}$ and $700 \mathrm{mg} / \mathrm{L}$ respectively. These high values suggest contamination. Generally, the flow progrades from north to south of the study area. The pattern and distribution of each parameters was contoured using Surfer 8 softwares. The flow pattern and distribution actually shows that the direction of flow of suspended particulate matter at CNAS and Zenith bank is symptomatic of contamination within these indicated positions.
\end{abstract}

Keywords: direction of flow, suspended solids, kwa river, particulate matter, boreholes, Umudike-Abia state

\section{Introduction}

The last decade has recorded an exponential need for accurate global groundwater resource assessment that has lead to a vast growing awareness in the area of groundwater development. As a result of these, quantitative description of aquifers has become a vital order to address myriads of hydrogeological problems. Water being a massive ,dynamic flowing body carries with it sometimes contaminants of varying degrees but most suspended particulate matter that are nearly colloidal in nature. Its permeability, transmissivity, aquifer depth, thickness, lateral extent and flow properties etc. are the essential but sometimes elusive factors in successful groundwater development and studies.

SPM is a synonym in earth sciences for suspended Particulate Matter. Suspended Particulate Matter (SPM) is "...sediment carried in suspension by the turbulent components of the fluid or Brownian movement (Wilber 1983). It is the residue in a well-mixed sample of water that will not pass through a standard, glass fibre $(0.45 \mu \mathrm{m})$ filter. Suspended sediments can also be called, suspended solids or suspended particles. A water body suspended load is a component of total turbidity. Generally, the suspended loads in flowing water consist of grains less than $0.5 \mathrm{~mm}$ in diameter. The reason for modeling of suspended sediments is that a special distribution of SPM is essential for describing biological processes in coastal waters deriving information on erosion or depositional system estimating water qualities for the community dwellers and to trace dispersion of contaminants which stick on SPM particles.

The objective of this paper is to assess the direction of flow of suspended particulate matter in boreholes located within the premises of MOUAU Umudike, Nigeria. To achieve this objective, characterization of the geological formations within the area through interpretation of geophysical data, hydrogeological analysis for aquifer characteristic and groundwater flow modeling of the area have been carried out. 
The Kwa Ibo River watershed is located between latitudes $5^{\circ} 19^{\prime}$ and $5^{\circ} 30^{\prime} \mathrm{N}$ and longitude $7^{\circ} 30^{\prime}$ and $7^{\circ} 37^{\prime} \mathrm{E}$. It covers a rectangular area of about $180 \mathrm{Km}^{2}$ which is bounded by Government College Umuahia, Ariam, Usaka Eleogu and Umuobia Olokoro. More specifically, Michael Okpara University of Agriculture Umudike, can be located at the latitude of $5^{\circ} 28.658^{\prime} \mathrm{N}-5^{\circ} 29.176^{\prime} \mathrm{N}$ and longitude of $7^{\circ} 32.256^{\prime} \mathrm{E}-7^{\circ} 32.803^{\prime} \mathrm{E}$. The location map of the University can be obtained in Figure 1.

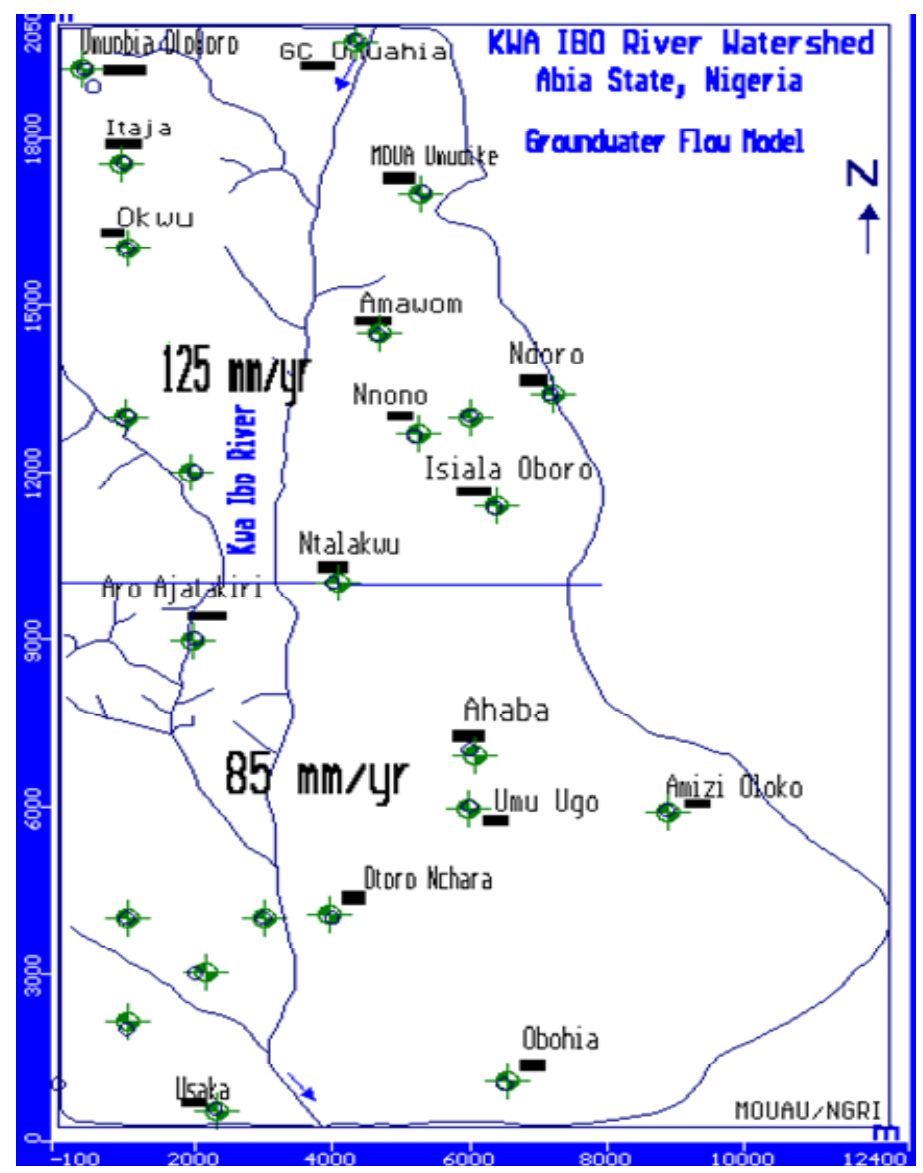

Figure 1. Map of the study area

There are two principal geological formations in the area, the latter are otherwise known as the Benin Formation. The late Tertiary to early Quaternary Benin Formation is most predominant (Mbonu et al., 1991) and uncomformably overlies the Bende-Ameki Formation, with a southwestward dip. The principal geological formations have a comparative groundwater regime. They both have reliable groundwater that can sustain regional borehole production.

Groundwater flow modeling is generally used to define the quantity of groundwater available or direction of dissolved migration. It is also used to define the limit of a capture zone for a contamination recovery well (or well field), or for delineating a water well protection area (or recharge area) for a water supply (Igboekwe \& Udoinyang, 2011).

Substances dissolved or suspended in groundwater reflect its quality. Suspended materials are not transported to a greater extent in most subsurface materials, but it is usually filtered out. In general, groundwater flow is very slow and depends on the permeability (water transmitting ability) of the subsurface materials, as well as the hydraulic gradient (slope of the water-table or pressure gradient for artesian conditions).

Groundwater flow is generally assumed to be governed by the relations expressed in Darcy's Laws and the conservation of mass. Darcy's Law is a derived constitutive equation that describes the flow of a fluid through a porous medium based on the results of experiments on the flow of water through beds of sand (Figure 2). It 
states that the rate of flow is directly proportional to the drop in vertical elevation between two places in the medium and directly proportional to the distance between them.

$$
Q=\frac{K A\left(H_{1}-H_{2}\right)}{L}
$$

$Q=$ ground water flow rate

$$
\begin{gathered}
\left(H_{1}-H_{2}\right)=\text { piezometric head drop } \\
\mathrm{A}=\text { Cross sectional area, A } \\
\mathrm{L}=\text { distance between wells }
\end{gathered}
$$

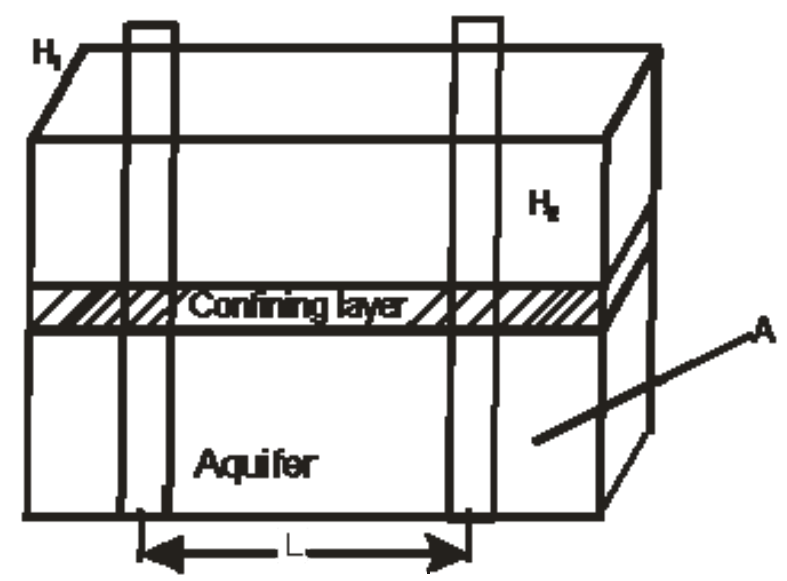

Figure 2. Diagram showing the rate of flow

The purpose of a model that simulates transport in groundwater is to compute the concentration of a dissolved chemical species in aquifer at any specified place or time. The theoretical basis for the equation describing solute transport has been well documented in the literature (Bear, 1997; Domenico \& Sebwartz, 1998). Reilly et al. (1987) provide a conceptual framework for analysing and modeling physical solute transport processes in groundwater. The development of mathematical equations that describes the groundwater flow and transport process may be developed from the fundamental principle of conservation of mass of fluid or of solute. Given a representative volume of porous medium, a general equation for conservation of mass for volume mass is expressed as:

Rate of mass inflow - (rate of mass outflow + rate of mass production/consumption) = Rate of mass accumulation

This statement of conservation of mass (or continuity equation) may be combined with a mathematical expression of the relevant process to obtain a different equation describing flow of transport (Bear, 1997; Domenico \& Schwartz, 1998; Freeze \& Cherry, 1979).

The rate of flow of water through a porous media is related to the properties of the water, the properties of the porous media and the gradient of the hydraulic head, as represented by Darcy's Law which can be written as;

$$
q_{i}=-k_{i, j} \frac{\partial h}{\partial x j}
$$

Where: $q_{i}=$ Specific discharge, $\mathrm{LT}^{-1}$

$k_{i, j}=$ hydraulic conductivity of the porous medium

$\mathrm{LT}^{-1}$ and $\mathrm{h}=$ hydraulic head, $\mathrm{L}$

A general form of the equation describing the transient flow of a compressible fluid in a non-homogeneous anisotropic aquifer may be derived by combining Darcy's Law with the continuity equation. A general groundwater flow equation may be written in Cartesian coordinate as; 


$$
\frac{\partial}{\partial x i}\left[k_{i, j} \frac{\partial h}{\partial x j}\right]=S_{s} \frac{\partial h}{\partial t}+W^{*}
$$

Where: Ss is the specific storage, $\mathrm{LT}^{-1}, \mathrm{t}$ is the time, $x i$ are Cartesian coordinates.

An expression similar to Equation (4) may be derived for the two-dimensional areal flow of a homogeneous fluid in a confined aquifer and written as:

$$
\frac{\partial}{\partial x i}\left[T_{i, j} \frac{\partial h}{\partial x j}\right]=S_{s} \frac{\partial h}{\partial x i}+W^{*}
$$

Where $T_{i, j}$ is the transmissivity, $\mathrm{LT}^{-1}$ and $T_{i, j}=T_{i, j} b j$

$\mathrm{B}=$ Saturated thickness of the aquifer, $\mathrm{L}$

$\mathrm{S}=$ Coefficient (dimensionless) and

$\mathrm{W}=W^{*} b$ is the volumetric flux per unit area. When the equation 4 is applied to an unconfined (water table) aquifer system, it must be assumed that the flow is horizontal and equipotential lines are vertical, that the horizontal hydraulic gradient equals the slope of the water table and storage coefficient is equal to specific yield (Sy) (Anderson \& Woessner, 1992).

The velocity of the flowing groundwater will obviously affect the migration and mixing of chemicals dissolved in groundwater. To calculate the actual seepage velocity of groundwater, one must account for the actual cross-section area through which the flow is occurring as follows:

$$
V=\frac{q_{i}}{\epsilon}=\frac{-K_{i, j}}{\epsilon} \frac{\partial h}{\partial x i}
$$

Where $\mathrm{V}_{\mathrm{i}}$ is the seepage velocity (also commonly called average linear velocity, $\mathrm{LT}^{-1}$ ) , and $\epsilon$ is the effective porosity of the porous medium.

An equation describing the transport and dispersion of a dissolved chemical in flowing groundwater may be derived from the principle of conservation of mass, equation (2), just as the general flow equation was derived (Bear, 1979; Domenico \& Schwartz, 1998; Konikow \& Groove, 1977; Igboekwe \& Udoinyang, 2011; Reddel \& Sunada, 1970).

A generalized form of the solute transport equation is presented by Groove (1976), in which terms are incorporated to represent chemical reaction and solute concentration both in the pore fluid and on the solid surfaces as

$$
\frac{\partial(q C}{\partial t}=\frac{\partial}{\partial x i}\left[\epsilon D i, j \frac{\partial C}{\partial x j}\right]-\frac{\partial}{\partial x i}(\epsilon C V i)-C^{1} W^{*}+C H E M
$$

Where CHEM equals;

$-\rho b \frac{\overline{\partial C}}{\partial t}$ for linear equilibrium controlled sorption or ion exchange,

$\sum_{k=1}^{c} R_{k}$ for $\mathrm{S}$ chemical rate controlled reaction and or

$-\lambda\left(\epsilon C+\rho_{b} C\right)$ for decay and where

$D_{i, j}$ is the coefficient of hydrodynamic dispersion, $L^{2} T^{-1}$

$C^{1}$ is the concentration of the solute in the source or sink fluid, $\bar{C}$ is the concentration of the species absorbed on the solid (mass of solute/mass of solid) $\rho, \rho_{b}$ is bulky density of the sediment, $M L^{-3}$

$R_{k}$ is the rate of production of the solute in reaction $\mathrm{K}, M L^{-3} T^{-1}$

$\lambda$ is the decay constant (equals to $\ln \frac{2}{T_{1 / 2}}, T^{-1}$ (Groove, 1976))

a factor $R_{f}$. The transport process thus appears to be "retarded" because of the instantaneous sorption into the porous medium. 


\section{Materials and Methods}

A geophysical survey was conducted in fourteen (14) stations within and close to MOUAU campus Umudike to obtain the vertical electrical sounding (VES) data using the Schlumberger resistivity sounding method. From the sounding, the characteristics of the aquifer in the Kwa Ibo river water shed was establish. Modeling of VES results was done using the RESIST software which is an iterative inversion-modeling program.

Table 1. Result of groundwater quality analysis of samples collected from selected boreholes in the study area

\begin{tabular}{lllllccccc}
\hline \multicolumn{1}{c}{ Location } & Elevation & Latitude & Longitude & P.H & $\begin{array}{c}\text { Suspended } \\
\text { Solids } \\
(\mathrm{Mg} / \mathrm{L})\end{array}$ & $\begin{array}{c}\text { Total } \\
\text { Dissolved } \\
\text { Solids } \\
(\mathrm{Mg} / \mathrm{L})\end{array}$ & $\begin{array}{c}\text { Turbidity } \\
(\mathrm{Ntu})\end{array}$ & $\begin{array}{c}\text { Conductivity } \\
\mu \mathrm{s} / \mathrm{Cm}\end{array}$ & $\begin{array}{c}\text { Total } \\
\text { Solids } \\
(\mathrm{Mg} / \mathrm{L})\end{array}$ \\
\hline PG HOSTEL & 117.3 & 5.4776 & 7.5423 & 4.71 & 350 & 150 & 98.8 & 100 & 500 \\
NRCRI CHAPEL & 123.7 & 5.4753 & 7.5438 & 5.04 & 200 & 100 & 89.2 & 66.7 & 300 \\
ENG. BLK & 91.2 & 5.4772 & 7.5398 & 6.90 & 250 & 350 & 90.5 & 233.3 & 600 \\
STAFF SCHOOL & 131.6 & 5.4893 & 7.5393 & 6.27 & 350 & 450 & 86.1 & 300 & 800 \\
MALE HOSTEL & 122.8 & 5.4807 & 7.5421 & 6.81 & 200 & 600 & 89.6 & 400 & 800 \\
ADMIN BLOCK & 125.4 & 5.4788 & 7.5435 & 5.27 & 300 & 600 & 92.6 & 400 & 800 \\
VC'S LODGE & 136.6 & 5.4852 & 7.5476 & 6.94 & 100 & 900 & 88.5 & 600 & 1000 \\
ZENTH BANK RESEARCH & 125.6 & 5.4848 & 7.5421 & 4.96 & 700 & 500 & 91.4 & 333.3 & 1200 \\
OPP UNI GATE & 127.4 & 5.4799 & 7.5464 & 4.98 & 400 & 400 & 91.8 & 266.8 & 800 \\
MPP6 UMUDIKE & 166.4 & 5.4719 & 7.5484 & 5.04 & 500 & 300 & 92.0 & 200.01 & 800 \\
CNAS & 103.3 & 5.4809 & 7.5398 & 5.49 & 120 & 900 & 88.7 & 600.03 & 2100 \\
\hline
\end{tabular}

Analysis of the resulting apparent resistivity versus the half-current electrode separation yielded layered earth models composed of individual layers of specified thickness and apparent resistivity. 11 samples of ground water were collected from the borehole wells located within and the immediate environs of MOUAU and also another set of 11 groundwater samples were obtained from the Kwa Ibo River that runs behind the university campus within the water shed. The river samples were collected at a distance of $100 \mathrm{~m}$ on the two sides of the river bounding the university community by stratified sampling. The samples were sterilized and analyzed for $\mathrm{pH}$, suspended solids, total dissolved solid, turbidity, electrical conductivity, total solids and temperature using the standard laboratory techniques. Spectrophotometer, HACH sension meter and HACH 44600-00 Conductivity/TDS meter at a temperature of $20^{\circ}$ was used. The results are presented in Table 2.

Table 2. Summary of parameter concentrations (for borehole locations)

\begin{tabular}{lllll}
\hline Parameter & Minimum & Maximum & Mean & WHO standard \\
\hline P.H & 4.71 & 6.94 & 5.47 & $6.50-8.50$ \\
Conductivity & 66.67 & 600.3 & 336.12 & 500.00 \\
Total dissolved Solids (mg/L) & 100.00 & 900 & 504.00 & 500.00 \\
Total suspended Solids (mg/L) & $100(7)$ & $1200.00(11)$ & 429.00 & 500.00 \\
Turbidity & 86.1 & 92.60 & 90.17 & 5.00 \\
\hline
\end{tabular}

Table 3. Summary of parameter concentrations (Kwa Ibo River)

\begin{tabular}{lllll}
\hline Parameter & Minimum & Maximum & Mean & WHO standard \\
\hline P.H & 4.92 & 6.37 & 5.64 & $600-800$ \\
Conductivity & 62.3 & 390.4 & 226.35 & 500.00 \\
Total dissolved Solids (mg/L) & 100 & 800 & 450.00 & 500.00 \\
Total suspended Solids (mg/L) & 200 & 900 & 550.00 & 500.00 \\
Turbidity & 77.8 & 85.3 & 81.55 & 5.0 \\
\hline
\end{tabular}




\section{Discussion}

\subsection{Groundwater Flow Direction in the Study Area}

Hydraulic head or piezometric head is a specific measurement of water pressure above a geodetic datum. It is usually measured as a water surface elevation, expressed in units of length, at the entrance (or bottom) of a piezometer. In an aquifer, it can be calculated from the depth to water in a piezometric well (a specialized water well), and given information of the piezometric elevation and screen depth.

Water entering an unconfined or confined well will stand at a particular level. This level is the hydraulic head and is actually the sum of three components, the pressure head, elevation head and velocity head. Therefore the distribution of hydraulic head through an aquifer system determines where groundwater will flow. Where the hydraulic head is constant, there is no flow. However, if there is a difference in the hydraulic head from the top to the bottom due to draining from the bottom, the water will flow downward, due to difference in heads, also called the hydraulic gradient. To determine the direction of flow of an aquifer in the study area, groundwater level measurement; relative geographic position of the wells and elevation were collected and contoured in map perspectives, (using surfer 8 software), thereby generating groundwater surface maps. The direction of groundwater movement can be understood in the fact that groundwater always flows in the direction of decreasing head. From the vector map (showing direction) for samples collected from Kwa Ibo River (Figure 3), it can be inferred that the water flows downwards from the river (North) with a higher hydraulic head (elevation) towards the well (south) located within the premises of MOUAU with lower hydraulic head. Similarly, the elevation map/direction of flow from modeling of water samples collected from borehole wells located within the MOUAU campus and its environs indicates that water flows towards the south west direction interacting with the groundwater from the Kwa Iboe River (Figure 4).

The movement rate on the other hand is dependent on the hydraulic gradient, which is the change in head per unit distance. It therefore follows from the analogy that the suspended particulate matter flows from the Kwa Ibo River into the borehole water wells located with the premises of Micheal Okpara University of Agriculture (MOUAU) -Umudike.

\subsection{Suspended Particulate Matter in Water Samples}

Table 2 shows the magnitude of loaded suspended particles in the borehole water samples analyzed in the laboratory. The suspended particulates in the analyzed borehole water samples ranged from 100 to $1200 \mathrm{mg} / \mathrm{L}$ with an average value of $414 \mathrm{mg} / \mathrm{L}$. Compared with the WHO standard, this pollutant seems to fall within the acceptable WHO standard. The groundwater within the indicated depths and locations in the table does not seem to be polluted. The suspended solids particles from river water samples were also investigated and the result is shown in Table 3.

The value of the suspended solids analyzed from Kwa Ibo River water samples ranged from 100 to $900 \mathrm{mg} / \mathrm{L}$ and the average value was found to be $518 \mathrm{mg} / \mathrm{L}$. Based on the flow interaction between the borehole water samples and the Kwa Ibo River samples (clustered arrows in Figures 3 and 4) S, the borehole water seems to be polluted with the highly loaded suspended particles present in the Kwa Ibo River water samples which continually recharges into it.

By applying surfer 8 software, contour maps showing the distribution of the suspended solids were obtained as shown in Figures $5 \mathrm{a}$ and $5 \mathrm{~b}$ and Figures $6 \mathrm{a}$ and $6 \mathrm{~b}$ for borehole water samples and Kwa Ibo River water samples respectively. Kwa Ibo River according to the elevation flow direction map (Figure 3) flows from north to south and in event acts as the main recharge of the selected boreholes in Michael Okpara University which flows in the southwest direction (Figure 4). The fairly high distribution of the suspended particles in Kwa Ibo River water samples is responsible for the high value of suspended particles in borehole water samples. 


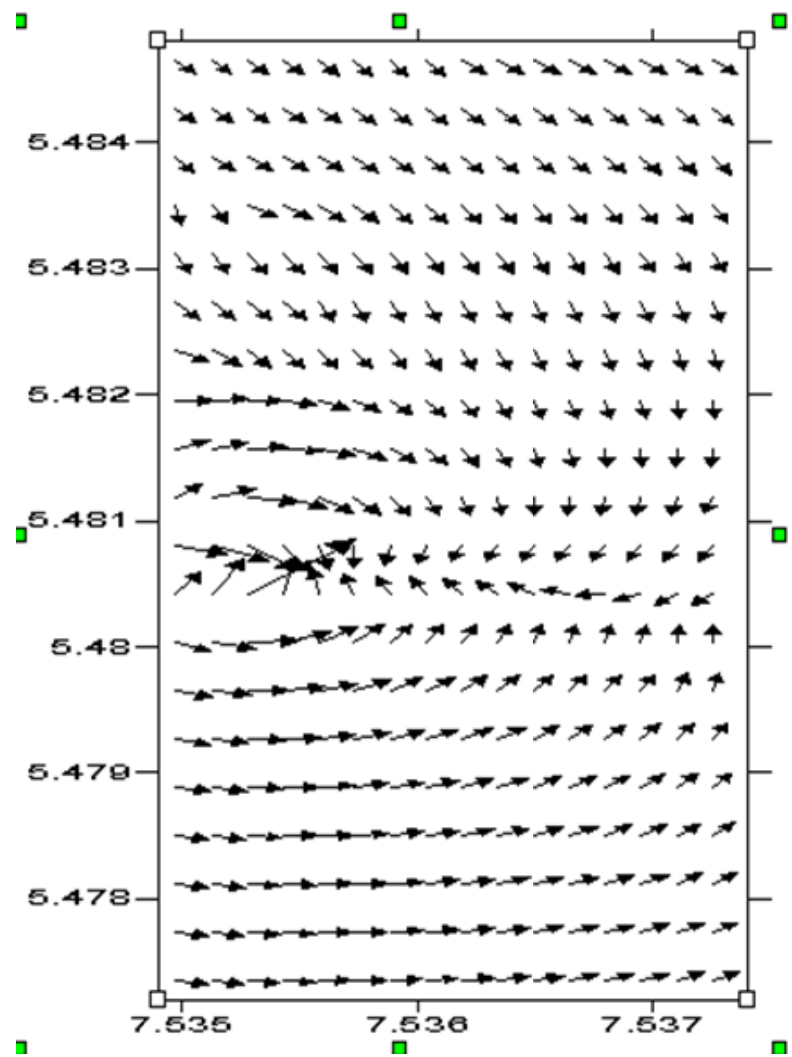

Figure 3. Flow direction for Kwa Ibo River

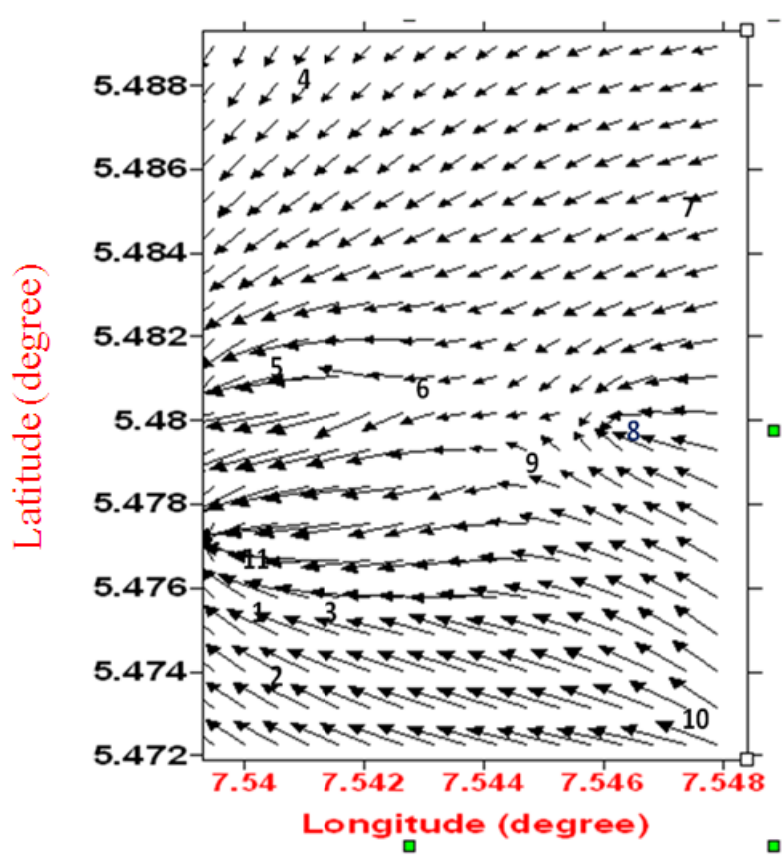

Figure 4. Flow direction for borehole water showing borehole locations in MOUAU 

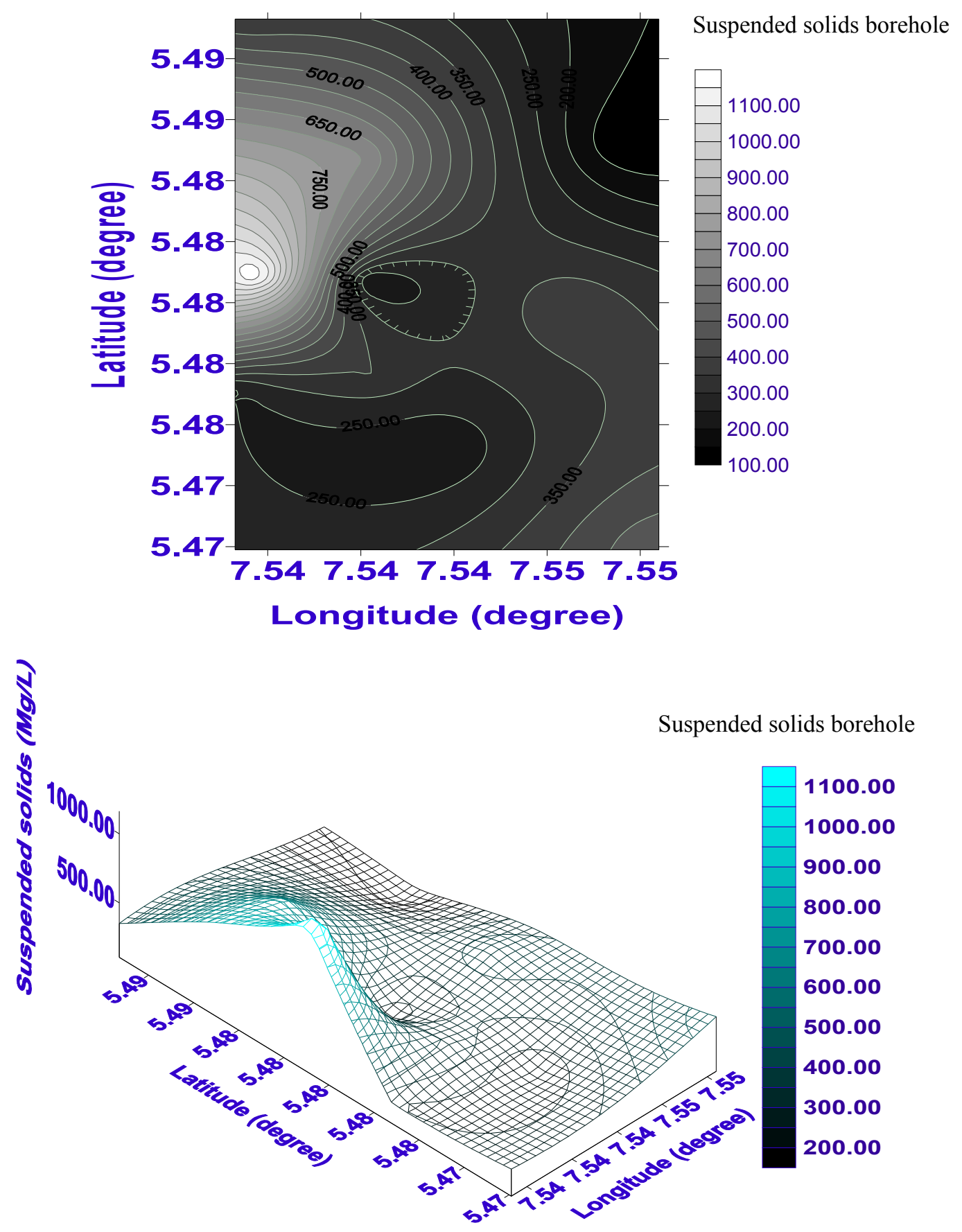

Figure 5. 2-D (a) and 3-D (b) contour map distribution for suspended solids in Borehole water 

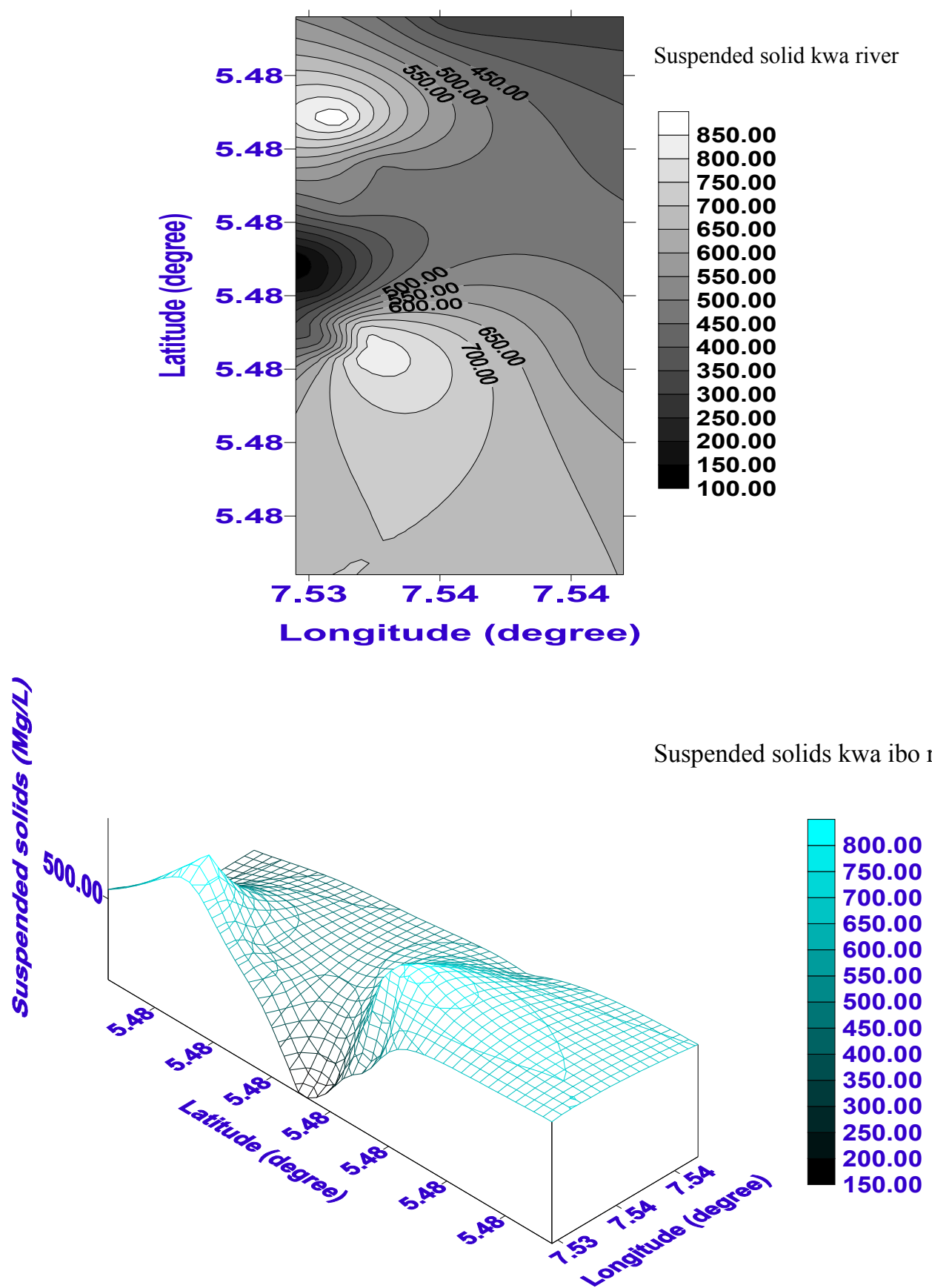

Figure 6. 2-D (a) and 3-D (b) contour maps suspended solids for Kwa Ibo River 


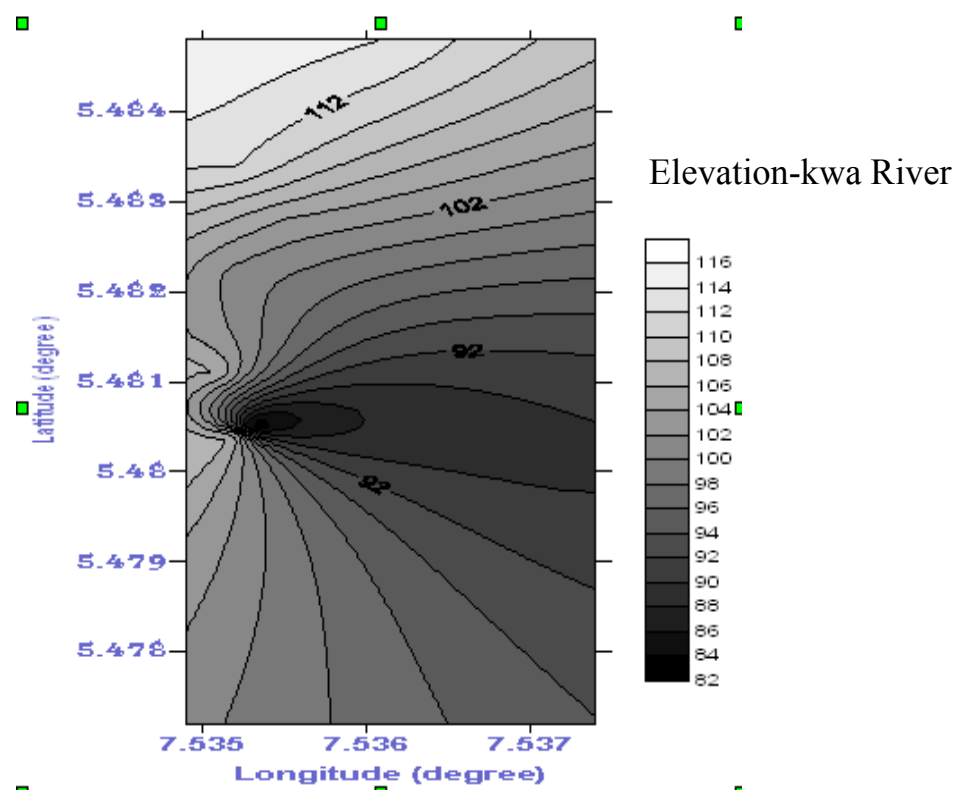

Figure 7. 2-D contour maps of for Kwa Ibo River

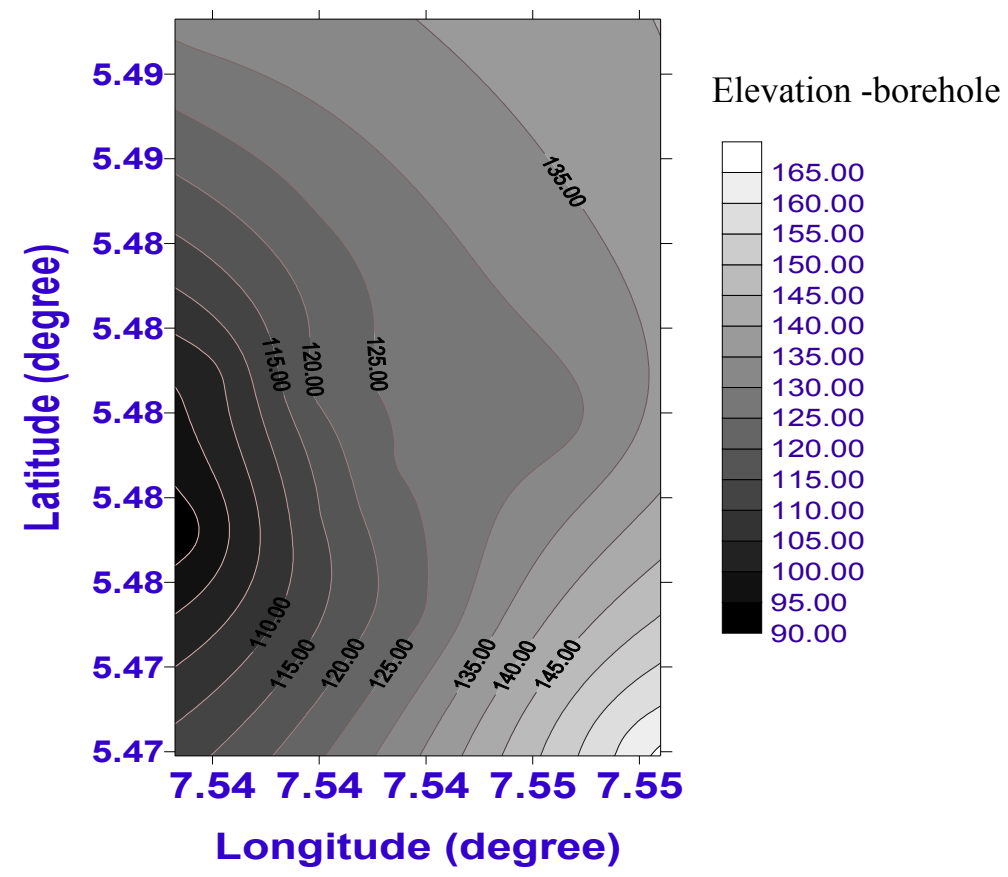

Figure 8. 2-D contour maps of elevation for Kwa Ibo River

\subsection{Hydrodynamics and Suspended Particulate Matter}

Water discharging from the Kwa Iboe River moves in the southward direction towards the wells located within the premises of MOUAU and then rotates towards the west due to coriolis acceleration and moves along the coast.

The data showing the total suspended solids distribution (Table 3) reveals that the river discharges an average of $518 \mathrm{mg} / \mathrm{L}$ total suspended solid concentration towards and into the wells $(414 \mathrm{mg} / \mathrm{L})$. Measured concentrations of the total solids concentration have been normalized to a mouth particle concentration equal to $909 \mathrm{mg} / \mathrm{L}$. The shape and extension of the plume shows the direction of flow towards the southwest, following the water circulation. 
The value of the total suspended solids obtained during the laboratory analysis is calculated for an average water discharge, and sedimentation increases after flood events when a larger amount of suspended matter is discharged by the river. High values of the total suspended solids are obtained in the vicinity of the river mouth, where the coarse particles are deposited.

\subsection{Dispersion of Pollutants}

The suspended particulate matter from the river is discharged into the borehole wells and the concentration follows the direction of the flow. There is an exchange between the pollutants that can be described in forms of kinetic transfer coefficient. It is assumed that absorption/release reactions are governed by a single reversible reaction. The total solids and the total suspended solid are transported by advection/diffusion process and those attached to the solid phase also settle with the settling velocity corresponding to the particulate class to which they are.

\section{Suggestion on the Control/ Reduction of Suspended Solid Concentration in Groundwater}

The suspended solid matter that flow from the kwa Ibo, River into the borehole wells in the university campus can be controlled in order to improve the groundwater quality in the study areas. These can be achieved by the following ways;

- Using infiltration practice to promote groundwater recharge, reduce run off peach flow and volume, and lessen the transport of non-point source pollutants to surface water body.

- $\quad$ Suspended solids are usually removed via straining by the soil.

- Where soil and groundwater conditions are favorable for artificial recharge of groundwater through infiltration basins, a high degree of upgrading can be achieved by allowing partially treated sewage effluent to infiltrate into the soil and move down into the groundwater. The unsaturated or "Vadose" zone then acts as a natural filter and can remove essentially all suspended solids, biodegradable materials etc.

- Avoid waste water outfall into to study area.

- As much as possible control the flow of sediments and nutrients from the farm into the river.

\section{References}

Anderson, M. P., \& Woessrev. (1992) Applied Groundwater modeling. San Diego: Academic Press, Inc. p. 381.

Bear, J. (1997). Introduction to Groundwater Hydraulics; A programmed Text for self - Instruction. Technologies of Water-Resistivity Investigation of the U. S. Geol. Survey, Book 3, Ch. B2: pp 172.

Domenico, P. A., \& Schwartz, F. W. (1998). Physical and chemical Hydrogeology (2 ${ }^{\text {nd }}$ ed.). New York: John Wiley \& Sons.

Freeze, R. A., \& Cherry, J. A. (1979). Groundwater Eagle Wood Cliffs. New Jersey: Prentice-Hall, 335-336.

Gelhar, L.W. (1993). Stochastic subsurface hydrology. Englewood Cliffs: Prentice Hall. Pp. 390.

Igboekwe, M. J., \& Udoinyang, I. E. (2011). Modelling of suspended particulate matter by kwa Ibo River, Umudike, South-eastern Nigeria. Implications for Pollutant dispersion. International Journal of Water Resources and Environmental Engineering, 3.

Konikow, L. F., \& Grove, D. B. (1977). Derivation of Equations Describing Solute Transport in Groundwater. Us Geol. Survey Water- Res. Inv. 77-79; pp 30.

Kumar, C. P. (1992). Groundwater Modelling in Hydrological Developments in India since Independence. A contribution to Hydrological Sciences, National Institute of Hydrology Roorkee, pp. 235-261.

Mbonu, D. D. C., Ebeniro, J. O., Ofoegbu, C. O., \& Ekine, A. S. (1991). Geo-electrical sounding for the determination of aquifer characteristics in parts of the Umuahia area of Nigeria of Nigeria. Geophysics, 56(5), 284-291.

Reddell, D. L., \& Sunada, D. K. (1970). Numerical Simulation of Dispersion in Groundwater Aquifers. Colorado State University, Ft. Collins, Hydrology Paper 41. Pp 79.

Reilly, T. E., Franke, O. L., Buxton, H. T., \& Bennet, G. D. (1987). A conceptual framework for ground-water solute - transport studies with emphasis on physical mechanics of solute movement. U.S. Geol. Survey Water - Res. Inv. Rept. 87-4191. Pp. 44.

Wilber, C. G. (1982). Turbidity in an aquatic environment an environmental factor in fresh and oceanic waters. Charles C. Thomas, Spring field IL. 